\title{
Relationship between Corporate Information Disclosure and Financial Performance in Saudi Arabia
}

\author{
Mohammad Hariri ${ }^{1}$ \\ ${ }^{1}$ College of Business Administration, Umm Al Qura University, Makkah, Saudi Arabia \\ Correspondence: Mohammad M Hariri, College of Business Administration, Umm Al-Qura University, Saudi \\ Arabia.
}

Received: December 27, 2021

Accepted: February 1, 2022

Online Published: February 14, 2022

doi:10.5539/ibr.v15n3p18

URL: https://doi.org/10.5539/ibr.v15n3p18

\begin{abstract}
This study explains the influence of the corporate disclosure of firms listed on the Kingdom of Saudi Arabia's stock exchange (Tadawul) on their subsequent financial performance. The research was conducted using an empirical-analytical approach at an explanatory level. Hypotheses were formulated based on secondary data and a general linear model that explains the financial performance measures based on the relevant corporate information disclosed by companies listed on Tadawul was used. Firms that disclosed the use of their strengths and resources to achieve objectives related to financial, economic, and environmental issues had a negative impact on the excess return expected beyond the systematic risk-adjusted return. Jensen's alpha index was found to be the most appropriate financial performance measure to evaluate the relationship between corporate disclosure practices and firms' subsequent performance. This study contributes to a better understanding of how the International Integrated Reporting Framework fosters value creation in financial capital. To the best of the author's knowledge, this is the first study to use statistical procedures to explain the simultaneous effects of multiple explanatory variables on multiple explained variables, which constitutes a major methodological contribution.
\end{abstract}

Keywords: corporate disclosure, financial capital, financial performance, integrated reporting, Saudi Arabia, voluntary disclosure

\section{Introduction}

In the last two decades, companies have faced growing demand to adopt policies related to social, environmental, and governance (ESG) issues (Hariri, 2021). Culture and society are questioning business organizations' emphasis on producing money, as this approach is limited and ignores the creation of value and justice for people, society, and the world (Dumay, Bernardi, Guthrie, \& Demartini, 2016).

Due of these challenges, stakeholders (investors, partners, employees, customers, suppliers, local communities, regulators, and policy makers) are demanding clear management of companies' ESG issues, forcing them to change their practices. Among these changes, corporate governance has found that corporate social responsibility (CSR) reports are adequate to meet such demands, which has led to a transformation in corporate reporting by increasing the voluntary disclosure of information on these issues.

Therefore, there is a need to create standards to strengthen and expand the quality of corporate information (Busco, Frigo, Quattrone, \& Riccaboni, 2013). For this purpose, various regulatory bodies and international standard issuers have emerged, such as the International Integrated Reporting Council (IIRC) - a global coalition of regulators, investors, companies, standard-setters, accounting professionals, and non-governmental organizations (NGOs) that share the vision that communicating value creation should be the next step in the evolution of corporate reporting (International Integrated Reporting Council [IIRC], 2013). To this end, the IIRC developed the "International $<\mathrm{IR}>$ Framework" and, currently, it has been widely accepted among organizations that have voluntarily disclosed corporate information (Busco et al., 2013). This theoretical framework proposes onto-epistemological foundations and methodological guidelines for corporate governance to address the preparation and disclosure of integrated reports (IRs).

Corporate governance adopts the IR' guidelines voluntarily and reveals the competitiveness of its financial return, possession and use of its tangible and intangible assets as a source of its competitive advantage, management of 
ESG issues, state of its relationships with its stakeholders, strategy, and the firm's organizational performance. It is worth asking whether this knowledge influences investors' decisions to include or exclude certain companies in their portfolio. If so, investors' decision is reflected in the firm's financial performance measures in the following fiscal year. Consequently, this study explains the influence of corporate disclosure by firms listed on Tadawul on their immediate subsequent financial performance. For this purpose, it is intended to build an empirical model that elucidates the association between the disclosure of the elements of the theoretical framework of IR (IIRC, 2013) in 2019 and various financial performance measures widely used by investors and fund managers in 2020. Such a model makes it possible to link corporate disclosure practices with the creation of value in the financial capital of firms, identify IR elements and financial performance measures relevant in relation to the IR international framework, and identify the kinds of firms that relate their corporate information disclosure patterns to their financial performance.

This article is organized as follows: Section 2 presents the theoretical framework of the IR, the financial performance measures, and prior research findings on the relationship between both constructs. In Section 3, the research hypotheses are formulated, and the study's plan is described. In Section 4, significant findings are presented, and the empirical model is built. Section 5 explains the findings and communicates new contributions to knowledge. Sections 6 and 7 summarize this study's contributions while declaring its implications and limitations.

\section{Theoretical Framework}

\subsection{Integrated Report Concept}

According to the IIRC's (2013) standards, an IR is defined as "a concise communication about how an organization's strategy, its corporate governance, performance and perspectives, in the context of its external environment, lead it to create value in the short, medium and long term" (p. 9). Its main purpose is to explain to the investors and other stakeholders (employees, customers, suppliers, partners, local communities, regulators, and policy makers) how an organization creates value over time. The IIRC (2013) maintains that value creation within an organization is determined by the external environment, resources used, and relationships with stakeholders. IR aims to provide a holistic view of these three determinants.

In its conceptualization, the IIRC (2013) calls "capitals" the resources used and the relationships linked to the organization. These capitals are categorized as financial, industrial, intellectual, human, social-relational, or natural. Financial capital comprises funds available to the organization to produce goods or provide services. This capital is obtained by contributions from investors through financing and/or is generated through operations. Industrial capital consists of fixed assets, such as buildings, machinery, and infrastructure, that the organization has available for use in the production of goods or the provision of services. Intellectual capital is an intangible asset based on the organization's knowledge, such as patents, copyrights, software, and licenses. The routines, procedures, and protocols developed by the company are also considered part of its intellectual capital.

The IIRC (2013) framework defines human capital as the competencies, capacities, and experiences of people, and their motivations to innovate, which include their ability to understand, develop, and implement the organization's strategy. It includes loyalty and motivation to improve processes, products, and services, their ability to direct, manage, and collaborate, and their respect for the regulatory framework, risk management, and the organization's ethical values. Social and relational capital refers to links with institutions, communities, interest groups, and other networks, and the ability to share information to improve individual and collective well-being. Social and relational capital includes common norms, values, and behaviors, the effort to build and protect relationships with external stakeholders, and the intangible value of the brand's reputation. Finally, natural capital is all renewable and non-renewable environmental resources and processes that provide goods and services that sustain the organization's past, current, or future prosperity.

In summary, an IR discloses how the organization interacts with the external environment and with the six capitals to create financial and non-financial value in the short, medium, and long term. It can be said that financial information constitutes shareholders' main interest, while stakeholders focus their attention on non-financial information (Appiagyei, Djajadikerta, \& Xiang, 2016).

\subsection{Elements of an Integrated Report}

According to the IIRC (2013), an IR consists of seven elements:

\subsubsection{Organizational Overview and External Environment}

This section describes what the organization does and its circumstances of operation, disclosure of its mission, vision, culture, ethics, and values. It identifies shareholders, operating structure, establishments, activities, and 
markets. Furthermore, this section describes factors of the general environment (political, economic, social, technological, legal, and environmental) and factors of the business environment (entry of new competitors, intensity of competition, power of suppliers and clients, and potential substitutes).

\subsubsection{Governance}

This section discusses how an organization's governance structure supports its ability to create value in the short, medium, and long term. It describes the structure of senior management, mechanisms to make strategic decisions, the establishment of culture, and evaluation of ethics and integrity. It also demonstrates the top management's knowledge of market forces, strategy implementation, and risk management. Similarly, it expresses the influence of culture, ethics, and values on the management of the six types of capital. Finally, it presents the role of governance in promoting innovation and linking remuneration and incentives to value creation.

\subsubsection{Business Model}

The third section presents the organization's business model. This implies exposing the input transformation system, through its business activities, in the products and results to fulfil the organization's strategic purposes and value creation in the short, medium, and long term. It includes explicit identification of the business model's elements, a simple diagram, the identification of stakeholders, and external factors that determine the business model. The link of the business model with the strategy and operational and financial performance of the organization or key performance indicators (KPIs) are provided.

\subsubsection{Opportunities and Risks}

This section outlines the specific opportunities and risks involved in the organization's ability to create value in the short, medium, and long term. It incorporates how the organization manages them. Furthermore, it includes those opportunities and risks that influence the organization's effects on the availability, quality, and affordability of relevant capital in the short, medium, and long term. This includes identifying the sources of risk or opportunity, assessing their magnitude, and developing specific measures to manage them.

\subsubsection{Strategy and Resource Allocation}

An IR indicates where the organization wants to go and how it plans to get there. The content includes its strategic objectives, strategies for achievement, resource allocation plans, and an achievement measurement system. Businesses must also demonstrate how their strategy and resource allocation plan relate to the business model and the six types of capital. Furthermore, it identifies the organization's competitive advantage and commitment to the stakeholders.

\subsubsection{Performance}

An IR demonstrates the extent to which an organization has achieved its strategic objectives. Moreover, it identifies its results' effect on its capital. Among other things, an IR contains quantitative and qualitative performance indicators, the effect of performance on the six capitals, the status of the relationship with stakeholders, a comparative analysis between past and present performance, and future perspectives. Furthermore, it identifies the performance indicators that link financial to non-financial components.

\subsubsection{Future Perspectives}

An IR realistically highlights expected changes in future expectations. Moreover, it emphasizes how an organization can be affected and its preparedness to face those changes. These perspectives can be estimated from the KPI sensitivity analysis.

\subsection{Financial Performance and Measures}

Financial performance is the measurement of the results of a firm's policies and operations in monetary terms, and refers to the rate of return of a financial asset at a level of risk acceptable to the investor (Hoa, 2010). This definition suggests that investors want to invest in securities that offer the best returns with a tolerable risk. Investment objectives vary from person to person with respect to return and risk tolerance, although investors tend to prefer the highest return with the lowest possible risk (Arif, Samim, Khurshid, \& Ali, 2019). Consequently, the predominant trend in empirical literature to measure financial performance consists of the return and risk assessments of investment (Climent, Molla, \& Soriano, 2020), prepared from the historical net asset value (NAV).

While the measurement and evaluation of financial performance are interesting, having several evaluation models makes it difficult for both academics and professionals to determine which model to use for measuring performance since there is no general theoretical framework that provides the evaluator with guidelines for their 
choice (AlRashidi, 2013). For this reason, financial performance can be evaluated based on the return to the investor, risk-adjusted returns, ability to invest in the best assets at the right time, and characteristics of the assets.

Financial performance measures based on risk-adjusted returns are mainstream in the literature. These measures can be of a single risk factor (using capital asset pricing model (CAPM), Treynor, Jensen, or Sharpe), may consider multiple risk factors (Carhart or Fama and French), or be derived from the former (e.g., timing and selectivity ability, MM, TT, or IR). Single-factor risk-adjusted return measures are the most popular tools to evaluate the financial performance of an individual asset or portfolio. The CAPM, Treynor ratio, and Jensen's alpha index can be used to measure the performance of both portfolios and individual securities. In contrast, the Sharpe index is unsuitable for evaluating individual securities. Measures to evaluate individual assets are described for the purposes of this study.

The CAPM is a single index measure for evaluating financial asset value. It satisfies the need for a benchmark to compare financial assets and mutual fund managers' performance.

Although simple, this model strongly interprets risk, which is the most crucial factor affecting financial assets (AlRashidi, 2013). The model reduces all forms of risk available to an asset by distinguishing between systematic (non-diversifiable) and unsystematic (diversifiable) risk. The beta coefficient ( $\beta$ ), which is the final product of the reduction, measures systematic risk; therefore, compared to other asset valuation models, this measure is easily understandable for investors.

The CAPM mainly describes the theory of the linear relationship between returns and risk (or mean-variance relationship). The expected return of an asset or portfolio is related to the excess expected return of the market portfolio, which is adjusted for the systematic risk of the asset or portfolio, and is commonly represented as

$$
R_{p}=R_{f}+\beta\left[R_{m}-R_{f}\right],
$$

where:

$\mathrm{Rp}$ is the expected excess return for an asset, $\mathrm{Rm}$ is the expected excess return for a market portfolio benchmark, $\mathrm{Rf}$ is the return from a risk-free asset, and $\beta$ is the measure of the systematic risk of the asset. $\beta$ is calculated as

$$
\beta=\frac{\operatorname{Cov}\left(R_{p}, R_{m}\right)}{\sigma_{m}},
$$

where:

Cov represents the covariance between the asset's return and that from the market and $\sigma \mathrm{m}$ is the variance of the market's returns.

The CAPM states that the only factor contributing to return variability is systematic risk, represented by $\beta$, because diversification eliminates all other forms of risk. This information simplifies the portfolio selection process, allowing investors to focus on a single risk factor.

The Treynor ratio is the excess return on the asset per unit of systematic risk ( $\beta$ ). The mathematical expression is as follows:

$$
\text { TreynorRatio }=\frac{\left(R_{p}-R_{f}\right)}{\beta},
$$

where:

$\mathrm{Rp}$ is the return from the asset, $\mathrm{Rf}$ is the return from the risk-free asset, and $\beta$ is the systematic risk. The higher the value of the Treynor ratio, the better it is for the investor (Elfakhani, Sidani, \& Fahel, 2004), as it means that more returns are obtained per additional unit of risk.

\subsubsection{Jensen's Alpha Index}

This index measures the excess return, if any, above (or below) the CAPM's performance (Elfakhani et al., 2004). Consequently, this can be expressed as follows:

$$
R_{p}=a_{p}+\left[R_{f}+\beta\left(R_{m}-R_{f}\right)\right]
$$

where:

$\alpha p$ is the return from a given portfolio above the return predicted by the CAPM. The value of $\alpha p$ is the intercept 
of the linear regression model of Rp as a function of CAPM (AlRashidi, 2013). For individual values, the value of $\alpha p$ is the difference between the observed return and the CAPM:

$$
\propto_{\mathrm{P}}=\mathrm{R}_{\mathrm{p}}-\mathrm{CAPM} \text {. }
$$

According to AlRashidi (2013), the theory underlying Jensen's alpha index is that an asset's performance can be measured by applying the constant term $\alpha p$ in the CAPM equation under the premise that a superior capacity in the selection of securities will allow a portfolio manager to select undervalued assets. Therefore, one will be able to generate higher and more consistent returns and prevail over the CAPM's predictions. In this scenario, the $\alpha p$ value will be positive, implying that the portfolio outperforms the market benchmark. Therefore, higher Jensen alpha values imply a higher return on assets.

\subsection{Relationship between Financial Performance and Integrated Reporting}

The international theoretical framework of IR (IIRC, 2013) repeatedly postulates that IR aims to improve the quality of information available to financial capital providers to make a more efficient and productive capital allocation. It demonstrates an organization's ability to create value for itself, allowing financial returns for investors. In other words, this theoretical framework proposes that corporate information disclosure is positively related to financial performance. In this sense, Appiagyei et al. (2016) argue that the benefits of the disclosure of IRs, promotion of "integrated thinking" within organizations, and associated cost savings should lead to the firm's improved financial performance. However, empirical evidence on this question has been controversial to date.

The literature review provided by Veltri and Silvestri (2020) concludes that the adoption and quality of an IR has positive economic impacts, regardless of the variable used to express the market result (i.e., share price, Tobin's Q, expected cash flows, liquidity of shares, and reduction of the cost of equity). Moreover, Lee and Yeo's (2016) sample of South African companies revealed that a firm's valuation is positively associated with the disclosure of its IR. This relationship is stronger in firms that are more complex. They also found that companies with high-level integrated reporting practices outperform those with low-level practices in both trading and accounting performance. Similarly, Barth, Cahan, Chen, and Venter (2016) found a positive relationship between IR quality, a firm's liquidity, and its future cash flows. Furthermore, the studies by Cosma, Soana, and Venturelli (2018) and Lopes, Oliveira, and Coelho (2017) support the hypothesis that IR adoption is positively related to a firm's market value.

In contrast, several other studies have not found a significant relationship between financial performance and IR disclosure practices. Although their conclusions support the association between IR and financial performance, Veltri and Silvestri (2020) acknowledged that a third of the documents analyzed in their systematic review do not show a significant relationship between them. Furthermore, Hurghiș (2015) concluded that a company's financial performance does not influence the extent to which its IR conforms to the IIRC (2013) framework. Interestingly, Sofian (2019) revealed that the disclosure practices of the IR are associated with the company's valuation, but not with its measures of return on assets (ROA) and return on equity (ROE). Churet and Eccles (2014) reported a similar result in a global sample of 2000 companies; they found no relationship between corporate information disclosure and ROE. Finally, Landau, Rochell, Klein, and Zwergel (2020), Soumillion (2018) and Wahl, Charifzadeh, and Diefenbach (2020) found no support for the hypothesis that IR disclosure practices reflect a firm's market value.

In summary, there is no consensus among academics on the relationship between IR disclosure practices and financial performance since the empirical evidence offers mixed results.

\section{Methodology}

\subsection{Research Approach and Design}

This study's objective is to model the relationship between corporate information disclosures of firms listed on Tadawul in 2019 and their financial performance in 2020. Therefore, this study was conducted under an empirical-analytical approach at an explanatory level in which, a set of contrasted hypotheses from secondary data reveals, in quantitative terms, a statistical model that explains financial performance measures as a function of the relevant corporate information disclosed by these companies.

\subsection{Population and Sample}

All non-financial sector companies listed in Tadawul at the end of 2020 were considered. Financial sector companies were excluded because they were subject to different types of regulations and standards. In total, 126 companies were scrutinized, of which 18 were excluded because they had missing financial measures. Therefore, 
the final sample consisted of 108 companies from 15 industrial sectors.

\subsection{Measurement of Key Constructs}

\subsubsection{Disclosure of Corporate Information}

Corporate information disclosure practices were obtained through a quantitative content analysis of the firms' corporate reports. Units of analysis were configured based on the content provided in Section 4 of the International Framework of IR (IIRC, 2013). In total, 45 items were established and distributed among the six elements of the IR: organizational overview and perspectives (six items), governance (six items), business model (seven items), risk and opportunities (12 items), strategy and resource allocation (seven items), and performance (seven items). These items were disclosed in Hariri (2021). The measurement, which consisted of verifying whether each item was disclosed in the corporate reports of the surveyed companies, was recorded on a dichotomous scale of two mutually exclusive categories: $1=$ not disclosed and $2=$ disclosed.

\subsubsection{Financial Performance}

To evaluate this variable, the following single-factor risk-adjusted return measures were used: CAPM, Treynor ratio, and Jensen's alpha index. These measures were selected because of their suitability in evaluating individual assets and portfolios. For each surveyed company, the values for these measures were obtained from the Market-Risk-Premia.com portal (2021) at the end of 2020. All these measures are continuous-scale variables.

With the data obtained, a case-variable database consisting of 50 columns (id, company name, 45 items of the IR, CAPM, Treynor ratio, and Jensen's alpha index) and 126 columns containing the data collected from each company was built using the statistical software IBM SPSS v.21.

\subsection{Research Hypotheses}

The IIRC (2013) framework postulates that an IR reveals the way in which a company creates value over time using resources, "the six capitals," which includes financial capital. The value produced by financial capital translates into a better return for investors. Hence, an IR is a valuable source of consultation for investors who wish to include or exclude certain firms.

In contrast, firms listed in Tadawul are not homogeneous in their voluntary disclosure practices (Hariri, 2021), as each, in its corporate report, emphasizes those aspects of the IR that are of particular interest to it. Therefore, the model calculates the effect of conglomerates of firms grouped according to their disclosure practices on financial performance measures.

Hence, considering how valuable a source IR could be and the impact it might have on Tadawul listed firms, this study's hypotheses in constructing the research model are as follows.

The first two hypotheses seek to detect the relationship between disclosure practices, clusters of firms, and financial performance measures.

H1A: Disclosure practices for one fiscal year are independent of the financial performance of the following fiscal year.

H1B: The disclosure practices of clusters of firms in a fiscal year are independent of their financial performance in the following fiscal year.

The following three hypotheses were intended to identify the relationship between each financial performance measure and disclosure practices separately.

H2A: The IR disclosure practices in a fiscal year are independent of the CAPM of the following fiscal year.

H2B: The IR disclosure practices of a fiscal year are independent of the Treynor ratio of the following fiscal year.

H2C: The IR disclosure practices for a fiscal year are independent of the Jensen's alpha index for the following fiscal year.

Finally, the following hypothesis seeks to prove that the effect of the distinctive disclosure practices of each cluster of firms is the same for financial performance measures.

H3: The means differences in financial performance measures between clusters of firms are zero.

\subsection{Analysis Techniques}

This study identified conglomerates of firms in accordance with the disclosure practices of their corporate information and subsequently related these conglomerates with their financial performance measures. A general 
equilibrium approach was followed to assess the effects of disclosure practices and financial performance measures comprehensively and simultaneously. Consequently, the general linear model (GLM) was selected as the analysis technique because it allows the evaluation of the effects between subjects and is a robust method in the face of deviations from normality. The procedure followed in the data analysis was as follows:

The 45 elements comprising the disclosure practices were reduced using principal component analysis (PCA) with varimax rotation. With the obtained components, the firms were classified into four clusters according to their predominant disclosure practices using K-means cluster analysis. Thereafter, the components that had a significant effect on the classification of firms were identified through a univariate analysis of variance (ANOVA), with a dependent variable in each firm's membership cluster, and its covariates were the main components obtained in the PCA. In summary, through the analyses described, a set of principal components was obtained that represented the disclosure practices having a significant effect on the clustering of firms. The principal components were standardized continuous variables. Clusters of firms were ordinal-type variables.

The CAPM, Treynor, and Jensen variables were standardized so that they were on a scale equivalent to disclosure practices; the associations that could exist between them were highlighted. Next, an exploratory analysis of the standardized performance measures (ZCAPM, ZTreynor, and ZJensen) was performed. In total, 18 cases with missing values in the ZTreynor variable were found and removed from the calculations. Similarly, four significant outliers were identified in ZTreynor and ZJensen. These outliers were handled by winsorizing for a significance level of $\alpha \leq 0.010$ (two-tailed). After preparing the data, only 108 cases were considered for the general linear model.

The GLM procedure was performed, in which ZCAPM, ZTreynor, and ZJensen were the dependent variables, the membership cluster was the grouping factor, and the principal components with a significant effect on the firm's classification were the covariates (independent variables). Therefore, the GLM was represented as a function of type:

$$
F(\text { ZCAPM }, \text { ZTreynor }, \text { ZJensen })=G(\text { group, components }) \text {. }
$$

The results of these procedures are discussed in the next section.

\section{Results}

The PCA performed on the disclosure of the 45 items of the IR produced a solution of 10 components with eigenvalues greater than 1 , which together explained $73.013 \%$ of the variance in the data, as shown in Table 1.

Table 1. Principal components of disclosure practices

\begin{tabular}{|c|c|c|c|c|c|c|}
\hline Component & Items & Eigenvalue & $\%$ Variance & $\mathrm{F}$ & $p$ & Denomination \\
\hline $\mathrm{C} 1$ & $\begin{array}{c}1,2,4,5,6.8,9,13,18, \\
24,28,30,35,37,38, \\
41,44,45\end{array}$ & 9.227 & 20.505 & 8.537 & $.004 *$ & IR elements (overall) \\
\hline $\mathrm{C} 2$ & $3,7,14,20,22,39,42$ & 6.855 & 15.233 & 8.532 & $.004^{*}$ & Strategic process \\
\hline $\mathrm{C} 3$ & $23,25,26,27,31$ & 2.810 & 6.244 & 55.034 & $.000^{*}$ & Orientation toward SRI \\
\hline $\mathrm{C} 4$ & 12,17 & 2.375 & 5.278 & 2.915 & .091 & \\
\hline $\mathrm{C} 5$ & $11,15,16,36$ & 2.366 & 5.259 & .013 & .909 & \\
\hline C6 & 34,43 & 1.979 & 4.398 & .056 & .814 & \\
\hline $\mathrm{C} 7$ & 19 & 1.915 & 4.255 & 118.513 & $.000^{*}$ & Waste management \\
\hline $\mathrm{C} 8$ & $21,32,33$ & 1.898 & 4.218 & 24.336 & $.000^{*}$ & $\begin{array}{c}\text { Strengths and allocate } \\
\text { resources to achieve strategic } \\
\text { objectives }\end{array}$ \\
\hline C9 & 10,40 & 1.875 & 4.167 & 102.779 & $.000^{*}$ & $\begin{array}{c}\text { Meets legal } \\
\text { requirements/Measures risks } \\
\text { and opportunities }\end{array}$ \\
\hline $\mathrm{C} 10$ & 29 & 1.555 & 3.456 & 3.460 & .066 & \\
\hline
\end{tabular}

$\mathrm{F}=$ test statistic; $p=$ level of significance reached; *significant at a level of $.05 ; \mathrm{IR}=$ socially responsible investment; SRI = socially responsible investment 
The adequacy of the data to the PCA was verified using three tests - the determinant of the correlation matrix tended to zero $(\mathrm{D}=10-13)$, the KMO coefficient was .843, and Bartlett's sphericity reached a level of significance of $\mathrm{p}<.010$. Taken together, these tests indicated that PCA was suitable to analyze disclosure practices.

The 10 components obtained represented disclosure practices, in which each firm had an optimal score for each component. Therefore, using K-means cluster analysis, the firms were grouped into four clusters based on their component scores. Within each cluster, the similarity between firms was maximized, whereas dissimilarity between clusters was maximized. Table 2 shows firms' conglomerates and their characteristics.

Table 2. Clusters of firms

\begin{tabular}{lcl}
\hline Cluster & $\mathrm{N}$ & Description \\
\hline 1 & 89 & $\begin{array}{l}\text { Conventional: General disclosure } \\
2\end{array}$ \\
3 & 8 & $\begin{array}{l}\text { Strategic: Emphasis on strategic issues } \\
\text { Socially responsible: Consideration of social and environmental issues in their } \\
\text { economic affairs } \\
\text { Environmentalists: Emphasis on compliance with the law, especially on } \\
\text { environmental issues }\end{array}$ \\
\hline $\mathrm{N}=$ number of firms in the cluster
\end{tabular}

$\mathrm{N}=$ number of firms in the cluster

Once the firms were classified as conglomerates, the components that contributed significantly to such classifications were investigated. For this, an ANOVA was performed, whose dependent variable was the cluster of firms, and its covariates were the 10 principal components obtained. The results of the $\mathrm{F}$ statistic and its significance level p indicated that six components $(\mathrm{C} 1, \mathrm{C} 2, \mathrm{C} 3, \mathrm{C} 7, \mathrm{C} 8$, and $\mathrm{C} 9)$ had a value of $\mathrm{p}<.010$, with a confidence level of $99 \%$, which revealed a significant contribution to the classification of the firms. Component C1 was composed of items from all elements of the IR; hence, it was named "IR elements (overall)." Component C2 linked issues of governance, markets, relationship with stakeholders, internal weaknesses, risks, measurement of objectives, and evaluation of present and future performance; that is, it suggested a "strategic process." Component $\mathrm{C} 3$ linked economic opportunities with social and environmental opportunities, which suggested an "orientation toward socially responsible investment (SRI)." Component C7 indicated "waste management." Component C8 dealt with the "use of strengths and allocation of resources to achieve the strategic objectives." Finally, C9 linked "compliance with legal requirements and the measurement of risks and opportunities." Table 1 presents the results.

Thereafter, the clusters of firms were characterized based on the names of the components that contributed to their formation. Cluster 1 consisted of 89 firms that met the IR requirements without emphasizing any aspect; these companies were called "Conventional." Cluster 2 was made up of six firms that emphasized the disclosure of their strategic aspects, such as their markets, relationships with their stakeholders, recognition of their internal weaknesses and economic risks, measurement of the achievement of their objectives, and linkage of present and future performance; this group of firms was designated as "Strategic." Cluster 3 consisted of seven firms that stood out in their disclosure on how they combine economic, social, and environmental opportunities (ESE); hence, they were termed "Socially Responsible." Finally, cluster 4 comprised six firms characterized by disclosing compliance with legal requirements, especially in environmental matters, while constantly monitoring their risks and opportunities; hence, they were named "Environmentalists."

Once the clusters of firms and the components that contributed to their formation were identified, the relationship between disclosure practices and financial performance were studied. The multivariate GLM procedure was used to test the following preliminary model for each of the three performance measures scrutinized:

where:

$$
\text { ZReturn }=\text { Intercept }+\sum_{i=1,2,3,7,8,9} B_{i} * C_{i}+M_{C}
$$

ZReturn is the expected value for each standardized performance measure (ZCAPM, ZTreynor, or ZJensen), Ci is the main component with a significant effect on the classification of firms, $\mathrm{Bi}$ are their corresponding correlation coefficients, and MC is the marginal mean of the performance measures in each cluster. This model was configured as follows: ZCAPM, ZTreynor, and ZJensen were the dependent variables; the principal components with a significant effect on the grouping of firms $(\mathrm{C} 1, \mathrm{C} 2, \mathrm{C} 3, \mathrm{C} 7, \mathrm{C} 8$, and $\mathrm{C} 9)$ were the covariates; 
and the cluster of firms was the grouping variable. The results obtained are as follows:

Hypotheses H1A and H1B indicated that performance measures are generally independent of firm clusters and disclosure practices. The GLM procedure performed a multivariate contrast of the preliminary model using multiple analysis of variance (MANOVA). The results are indicated in Table 3.

Table 3. Multiple analysis of variance (MANOVA)

\begin{tabular}{lrrrr}
\hline \multicolumn{1}{c}{ Component } & \multicolumn{1}{c}{$\mathrm{F}(p)$} & $\mathrm{F}(p)$ ZCAPM & $\mathrm{F}(p)$ ZTreynor & \multicolumn{1}{c}{$\mathrm{F}(p)$ ZJensen } \\
\hline Intercept & $2.226(.090)$ & & \\
$\mathrm{C} 1$ & $.410(.746)$ & & & \\
$\mathrm{C} 2$ & $.072(.975)$ & & & \\
$\mathrm{C} 3$ & $3.460(.019) *$ & $.000(1.000)$ & $1.086(.300)$ & $7.365(.008) * *$ \\
C7 & $.357(.784)$ & & & \\
C8 & $3.240(.025) *$ & $2.749(.101)$ & $5.610(.053)$ & $7.210(.009) * *$ \\
C9 & $.357(.784)$ & & & \\
Clusters & $2.261(.018) *$ & $.119(.948)$ & $.752(.524)$ & $4.799(.004) * *$ \\
Adjusted Model & & $.555(.830)$ & $1.252(.273)$ & $1.887(.047) *$ \\
\hline
\end{tabular}

$\mathrm{F}=$ test statistic. $P=$ significance level. $*$ significant at level $.05 . * *$ significant at level .01

For hypothesis H1A, the results revealed that only components $\mathrm{C} 3(\mathrm{~F}=3.460, \mathrm{p}=.019)$ and $\mathrm{C} 8(\mathrm{~F}=3.240, \mathrm{p}$ $=.025$ ) reached significance levels of $\mathrm{p}<.05$; hence, these components, with a confidence level of $95 \%$, had a significant effect on performance measures. The other components and the intercept reached a level of significance higher than $\mathrm{p}=.05$; hence, their effect was not statistically different from zero. In other words, corporate information disclosure and financial performance are not independent; therefore, the H1A hypothesis was not accepted. These findings revealed that disclosing how a firm uses its strengths, allocates resources to achieve its economic and financial objectives, and considers social and environmental issues significantly affects financial performance.

Hypothesis H1B attempted to test the independence of firm clusters' distinctive disclosure practices and overall financial performance measures. Table 3 shows that the variable clusters $(F=2.264, p=.018)$ had a significant effect on the performance measures at a $95 \%$ confidence level. This means that the clusters' disclosure practices of firms are associated with the performance measures. Consequently, the H1B hypothesis could not be accepted.

Hypotheses $\mathrm{H} 2 \mathrm{~A}, \mathrm{H} 2 \mathrm{~B}$, and $\mathrm{H} 2 \mathrm{C}$ meant to test the independence of corporate disclosure practices with performance measures separately by assessing the size of between-subject effects. Consistent with the findings of the multivariate contrasts, MANOVA found that ZJensen had a significant association with $\mathrm{C} 3(\mathrm{~F}=7.365, \mathrm{p}$ $<.01)$ and with $\mathrm{C} 8(\mathrm{~F}=7.210, \mathrm{p}<.01)$, at a confidence level of $99 \%$. Consequently, the H2C hypothesis was not accepted. In contrast, the effects between the IR disclosure practices with ZCAPM and ZTreynor obtained $\mathrm{p}>$ 0.05 , which indicated that the effect size between the variables was not statistically different from zero; that is, these two measures of financial performance are independent of disclosure practices. Hence, hypotheses $\mathrm{H} 2 \mathrm{~A}$ and $\mathrm{H} 2 \mathrm{~B}$ were accepted.

Testing hypotheses H2A and H2B revealed that the CAPM and the Treynor index are independent measures of firms' disclosure practices; hence, they were discarded from the model. On the contrary, the significant association between Jensen's alpha index and financial performance was revealed; therefore, only this performance measure was considered in the remaining analyses.

Hypothesis $\mathrm{H} 3$ attempted to test whether the effect of each cluster's distinctive disclosure practices had a significant effect on performance measures. The GLM procedure estimated the marginal mean of ZJensen in each cluster and calculated the difference in the means between them. Table 4 presents the results. 
Table 4. ZJensen marginal means and mean difference matrix

\begin{tabular}{lrrrrr}
\hline & Estimated Mean & \multicolumn{1}{c}{ Cluster 1 } & Cluster 2 & Cluster 3 & Cluster 4 \\
\hline Cluster 1 & .186 & $\mathrm{xxx}$ & & & \\
Cluster 2 & -.313 & -.499 & $\mathrm{xxx}$ & & \\
Cluster 3 & -2.605 & $-2.791^{* *}$ & $-2.292^{* *}$ & $\mathrm{xxx}$ & \\
Cluster 4 & .066 & -.120 & .379 & $2.670^{* *}$ & $\mathrm{xxx}$ \\
\hline
\end{tabular}

** significant at level .01

The statistical significance of the cluster-grouping variable on the performance measures indicated that at least one of the clusters of firms was associated with them. In the examination of the matrix of differences of means in Table 4, it was found that the estimated marginal mean of ZJensen in the Cluster 3 was significantly different from the marginal means of the other clusters at a confidence level of $99 \%$, which implied that Cluster 3 had a significant effect $\mathrm{MC}=-2.605$ on ZJensen. In turn, no significant mean difference was found in the ZJensen measure of the other clusters, whose values were close to zero, which implied that the effect size of clusters 1,2 , and 4 on ZJensen was statistically null. These surprising findings suggested that "socially responsible" firms have a negative effect on financial performance, whereas other categories of companies are not associated with it.

Finally, once the research hypotheses were tested, the initial model was corrected based on the significant findings presented thus far and the Bi correlation coefficients were estimated using the GLM procedure. The resulting model is as follows.

where:

$$
\text { Expected ZJensen }=.455 * C_{3}+.288 * C_{8}+M_{C},
$$

$\mathrm{MC}=-2.605$ for firms in Cluster 3 and $\mathrm{MC}=0$ for companies in other clusters.

The GLM procedure estimated that the effect size of the corrected model on Jensen $(F=1.887, p<.05)$ was significant at the $95 \%$ confidence level, as shown in Table 3 . The data used to apply this model are available from Hariri (2021).

The corrected model expressed that the standardized Jensen alpha index was a function of the C3 component (conjugation of economic, social, and environmental opportunities), C8 component (use of strengths and resources to achieve strategic objectives), and estimated marginal mean of the clusters. Table 1 lists the items comprising each component of the model.

For practical purposes, the Jensen's Alpha value predicted by the model for each asset in the portfolio was obtained through the following transformation:

$$
\mathrm{E}\left(\propto_{\mathrm{i}}\right)=\bar{\propto}_{\mathrm{p}}+\sigma_{\mathrm{p}} *\left(.455 * \mathrm{C}_{3}+.288 * \mathrm{C}_{8}+\mathrm{M}_{\mathrm{C}}\right),
$$

where:

$\mathrm{E}(\alpha i)$ is the expected value of Jensen's alpha for each asset in the portfolio (Tadawul), $\bar{\alpha}$ is the average value of Jensen's alpha in Tadawul, and $\sigma p$ is the standard deviation of Jensen's alpha in this portfolio.

To evaluate this model's predictive value, the difference between the observed and expected values of standardized Jensen's alpha for each Tadawul asset was calculated and subjected to a student's t-test, which indicated no significant difference from zero $(t=1.300, \mathrm{p}=.196)$ at a $95 \%$ confidence level. Given that there was no significant difference between the expected and observed values, it was concluded that the corrected model was appropriate to predict the excess return above the CAPM of the Tadawul portfolio.

\section{Discussion}

This study's purpose included explaining the influence of corporate information disclosure practices of firms listed in Tadawul, Kingdom of Saudi Arabia (KSA) on their subsequent financial performance, and building an empirical model to elucidate the association between the disclosure practices of firms in 2019 and the various financial performance measures in 2020.

Before discussing the merits of the matter under investigation, the firms were characterized. From the careful treatment and examination of 45 items from the content analysis of their corporate reports, 10 independent components representing different disclosure practice patterns were obtained. The firms were classified into four clusters - conventional, strategic, socially responsible, and environmentalists, according to these patterns. The 
intra-subject and inter-subject relationships of the components, clusters of firms, and financial performance measures were simultaneously analyzed with the GLM procedure. The results were obtained at three levels of depth.

At the most superficial level, MANOVA multivariate contrast was used to test Hypotheses H1A and H1B. The existence of a significant relationship between components $\mathrm{C} 3$ and $\mathrm{C} 8$, the clusters of firms, and the performance measures of the following fiscal year was revealed. This finding inserts the research into the mainstream of the literature (Appiagyei et al., 2016; Barth et al., 2016; Cosma et al., 2018; Lee \& Yeo, 2016; Lopes et al., 2017; Veltri \& Silvestri, 2020) that support the hypothesis that there is a relationship between IR disclosure and financial performance, whatever its measurement. However, the current study expanded the knowledge about this relationship, as it deepened the search for relevant associations between its constituent parts, such as financial performance measures, the types of firms in the Tadawul portfolio, and the disclosure patterns of corporate information.

The constitution of components C3 (items 23, 25, 26, 27, and 31) and C8 (items 21, 22, and 33) indicated that the disclosure of strengths and resources for achieving strategic objectives that combine economic aspects with social and environmental issues influence firms' subsequent financial performance. This unexpected finding suggested an association between financial performance and the disclosure of some ESG issues involved in IR. Furthermore, it was revealed that the cluster variable was significantly associated with financial performance; thus, it can be deduced that at least one of the clusters of firms is linked.

At the second level, inter-subject effects were examined to test hypotheses H2A, H2B, and H2C. Only ZJensen was significantly related to $\mathrm{C} 3$ and $\mathrm{C} 8$. Therefore, the CAPM and Treynor index are not adequate measures to evaluate the relationship between the disclosure of corporate information and financial performance. Hence, the excess return, positive or negative, measured by Jensen's alpha index is the most appropriate measure to estimate the future performance (higher or lower) of a portfolio based on its disclosure practices.

At the third level, the GLM procedure described the types of disclosure practices associated with the financial performance in the following fiscal year. The four clusters of firms were contrasted by examining their differences in ZJensen marginal means. Cluster 3, with firms that disclosed issues with socially responsible traits, had a marginal mean different from zero $(\mathrm{M} 3=-2.605)$ and a mean difference that differed significantly from other clusters. This finding indicated that firms with ESG-oriented disclosure practices have a negative effect on their subsequent financial performance. That is, the model predicts that such companies will underperform, as predicted by the CAPM.

The previous analyses revealed that in a portfolio of Tadawul firms, the disclosure practices of those companies that prioritize economic, social, and environmental issues in their strategy have a negative effect on subsequent financial performance, as expressed by Jensen's Alpha measure. This effect manifests itself at a lower level of performance than that expected by the CAPM.

\section{Limitations and Further Implications}

The present study has important theoretical implications. It went beyond establishing the associations between the variables and made it possible to identify the determining items of the IR, type of firms, most appropriate performance measure, and size of the effect of these relationships on the Tadawul portfolio. Furthermore, an empirical model of utility for IR practitioners was provided, which allows quantification of the financial value due to the disclosure of corporate information. Consequently, this study sheds light on how the fundamentals of the international IR framework generate value in financial capital.

To the best of the author's knowledge, this is the first study to use statistical procedures to explain the simultaneous effects of multiple explanatory variables on multiple explained variables, which constitutes a major methodological contribution to a better understanding of the influence of IR on financial performance.

The most important limitation of this study is that its results are applicable to firms in the Tadawul portfolio only because the data collected were circumscribed in this context. Therefore, the conclusions are only valid for the KSA stock exchange. Hence, it is of interest to use this methodology in a regional or international context that allows the contributions of this study to be generalized.

\section{Conclusions}

This study's purpose was to explain the relationship between corporate information disclosure practices and the financial performance in the following fiscal year, using firms listed on the KSA stock exchange (Tadawul). An empirical model was built using the general linear model statistical procedure, with which the simultaneous effects of the explanatory and explained variables were evaluated, and the correlation coefficients of the model 
were estimated. This study concludes the following:

All the IR elements were evaluated in this study. However, it was found that only those issues that link the use of strengths and resources to achieve economic, environmental, and social objectives are associated with firms' subsequent financial performance. Therefore, IR ESG topics are relevant to financial performance.

Furthermore, the study considered three measures of financial return adjusted to single-factor risk-CAPM, Treynor ratio, and Jensen's alpha index. The GLM procedure found that only Jensen's alpha was linked to disclosure practice. Therefore, disclosure practices do not affect the expected return estimated by the CAPM but do influence, positively or negatively, the excess of return denoted by Jensen's Alpha.

During the preparatory analysis, Tadawul firms were classified into four clusters according to their disclosure patterns. These clusters of firms were named conventional, strategic, socially responsible, and environmentalists. The GLM procedure indicated that only companies belonging to the socially responsible cluster had a significant effect on Jensen's alpha index, which was measured by the cluster's marginal mean. This effect size was negative, which implies that firms with a strategic orientation toward ESG issues have a lower return than expected by the CAPM since the excess return provided by Jensen's alpha index was negative.

In summary, this study reveals that among the firms in the Tadawul portfolio, the disclosure practices of companies that use their strengths and resources to achieve strategic objectives related to economic, social, and environmental issues have a negative effect on subsequent financial performance, as expressed by Jensen's alpha index. Firms with other disclosure practices have no effect on their subsequent financial performance. Therefore, Jensen's alpha index is the most appropriate measure to evaluate companies' financial performance in the context, since disclosure practices do not directly affect the systematic risk-adjusted return, but they do act on the excess of return that represents Jensen's alpha index.

\section{References}

AlRashidi, F. (2013). Comparison of the performance of Islamic mutual funds vs. ethical and conventional mutual funds (Doctoral dissertation, Durham University). Retrieved from http://etheses.dur.ac.uk/7340/

Appiagyei, K., Djajadikerta, H. G., \& Xiang, D. (2016). Integrated reporting and firm performance: A research framework. In ECU business doctoral and emerging scholars colloquium 2016 (pp. 123-129).

Arif, M., Samim, M. M., Khurshid, M. K., \& Ali, A. (2019). Islamic versus conventional mutual funds performance in Pakistan; Comparative analysis through performance measures and DEA approach. European Online Journal of Natural and Social Sciences, 8(1), 76-94. Retrieved from https://european-science.com/eojnss/article/view/5409

Barth, M. E., Cahan, S. F., Chen, L., \& Venter, E. R. (2016). The economic consequences associated with integrated report quality: Early evidence from a mandatory setting. Retrieved from https://www.en.iuc.bwl.uni-muenchen.de/arw/paper_arw-marybarth_09_05_16.pdf

Busco, C., Frigo, M. L., Quattrone, P., \& Riccaboni, A. (2013). Towards integrated reporting: Concepts, elements and principles. In C. Busco, M. L. Frigo, A. Riccaboni, \& P. Quattrone (Eds.), Integrated reporting: Concepts and cases that redefine corporate accountability (pp. 3-18). Springer International Publishing. https://doi.org/10.1007/978-3-319-02168-3_1

Churet, C., \& Eccles, R. G. (2014). Integrated reporting, quality of management, and financial performance. Journal of Applied Corporate Finance, 26(1), 56-64. https://doi.org/10.1111/jacf.12054

Climent, F., Mollá, P., \& Soriano, P. (2020). The investment performance of U.S. Islamic mutual funds. Sustainability, 12(9), 3530. https://doi.org/10.3390/su12093530

Cosma, S., Soana, M. G., \& Venturelli, A. (2018). Does the market reward integrated report quality? African Journal of Business Management, 12(4), 78-91. https://doi.org/10.5897/AJBM2017.8469

Dumay, J., Bernardi, C., Guthrie, J., \& Demartini, P. (2016). Integrated reporting: A structured literature review. Accounting Forum, 40(3), 166-185. https://doi.org/10.1016/j.accfor.2016.06.001

Elfakhani, S., Sidani, Y. M., \& Fahel, O. A. (2004). An assessment of the performance of Islamic mutual funds. European Journal of Management and Public Policy, 3(1), 41-64.

Hariri, M. (2021). Structure of integrated reporting, voluntary disclosure and firm-specific characteristics in Saudi Arabian companies. International Journal of Business and Management, 16(10), 73-85. https://doi.org/10.5539/ijbm.v16n10p73

Hoa, N. T. (2010). The impact and importance of activity based costing on financial performance of 
manufacturing firm (HELP University College, Malaysia). Retrieved from http://113.190.240.60:8080/phamquangquyen/bitstream/123456789/909/1/Nguyen\%20Thanh\%20Hoa.pdf

Hurghiş, R. (2015). Integrated reports and financial performance: An analysis. Paper presented at EUFIN 2015, Paris. Retrieved from https://www.researchgate.net/profile/Rares-Hurghis/publication/330215510_Integrated_reports_and_financi al_performance_an_analysis/links/5c34810f92851c22a363bd36/Integrated-reports-and-financial-performan ce-an-analysis.pdf

International Integrated Reporting Council. IIRC. (2013). The international $\langle I R\rangle$ framework. Retrieved from https://www.integratedreporting.org/wp-content/uploads/2015/03/13-12-08-THE-INTERNATIONAL-IR-F RAMEWORK-2-1.pdf

Landau, A., Rochell, J., Klein, C., \& Zwergel, B. (2020). Integrated reporting of environmental, social, and governance and financial data: Does the market value integrated reports? Business Strategy and the Environment, 29(4), 1750-1763. https://doi.org/10.1002/bse.2467

Lee, K. W., \& Yeo, G. H. H. (2016). The association between integrated reporting and firm valuation. Review of Quantitative Finance and Accounting, 47(4), 1221-1250. https://doi.org/10.1007/s11156-015-0536-y

Lopes, A. I., Oliveira, J., \& Coelho, A. M. C. (2017). How relevant is integrated reporting? In XVI Congresso internacional contabilidade e auditoria. Retrieved from https://repositorio.iscte-iul.pt/handle/10071/16358

Sofian, I. (2019). Does an improved type of reporting lead to a better financial performance? Journal of Accounting and Management Information Systems, 18(1), 73-100. Retrieved from https://www.ceeol.com/search/article-detail $\mathrm{id}=758757$

Soumillion, V. (2018). The value relevance of integrated reporting in South Africa (Master's thesis, University Gent, Belgium). Retrieved from https://libstore.ugent.be/fulltxt/RUG01/002/509/073/RUG01-002509073_2018_0001_AC.pdf

Veltri, S., \& Silvestri, A. (2020). The value relevance of corporate financial and nonfinancial information provided by the integrated report: A systematic review. Business Strategy and the Environment, 29(8), 3038-3054. https://doi.org/10.1002/bse.2556

Wahl, A., Charifzadeh, M., \& Diefenbach, F. (2020). Voluntary adopters of integrated reporting-Evidence on forecast accuracy and firm value. Business Strategy and the Environment, 29(6), 2542-2556. https://doi.org/10.1002/bse.2519

\section{Copyrights}

Copyright for this article is retained by the author(s), with first publication rights granted to the journal.

This is an open-access article distributed under the terms and conditions of the Creative Commons Attribution license (http://creativecommons.org/licenses/by/4.0/). 